\title{
IMPROVEMENT OF THE MODEL OF AN INNOVATIVE UNIVERSITY-TYPE CLUSTER IN A CASE EXAMPLE OF COORDINATED INTERNATIONAL ORGANIZATIONS INVOLVED IN THE METALLURGICAL INDUSTRY
}

\author{
${ }^{1}$ Sofiya SHEVTSOVA, ${ }^{2}$ Kamila JANOVSKÁ, ${ }^{3}$ Daria STRAPOLOVA, ${ }^{4}$ Vladimir MENSHIKOV, \\ ${ }^{5}$ Jakub CHLOPECKÝ \\ 1,2,3VSB - Technical University of Ostrava, Ostrava, Czech Republic, EU, sofiya.shevtsova.st@vsb.cz, \\ kamila.janovska@vsb.cz, daria.strapolova.st@vsb.cz \\ ${ }^{4}$ MUCTR - D. Mendeleev University of Chemical Technology of Russia, Moscow, Russia, vm uti@muctr.ru \\ ${ }^{5}$ CEVYKO a. s., Haviřov, Czech Republic, EU, chlopecky@cevyko.cz
}

https://doi.org/10.37904/metal.2021.4287

\begin{abstract}
The need to innovate in a difficult economic situation has become particularly important in recent years and has attracted the attention of many industrial economists. The cooperation of companies in networks and clusters has been recognized as a catalyst for accelerating industrial transformation for the development of new regional competitive advantages, accelerating the creation of companies and jobs. A large number of modern studies on the grouping of industrial enterprises and universities strongly recommend the use of this type of business combination to gain a number of advantages: better access to suppliers, innovation and competitiveness. Recently, however, more and more researchers are conducting a deeper analysis of the effectiveness of cluster companies and identifying a number of shortcomings. This suggests that the current most common model of university-type unification, namely the innovation cluster, is underdeveloped and requires transformation. Based on the study of this area of knowledge, it was concluded that emphasis should be placed on developing model and organizational aspects of fusion, as this is an obstacle for many clusters. In this article, an architectural model of a new type of university industry type cluster was developed, which contains elements of system analysis and logistic modeling. The effectiveness of innovation will be assessed on the example of associations of universities and industry with the participation of Czech and Russian partners.
\end{abstract}

Keywords: Clustering, modeling of management processes in industry, university-industry cluster, cluster management.

\section{INTRODUCTION}

The accumulated knowledge and potential for innovation of higher education institutions has significant importance in the growing role of intellectual capital in the development of economies [1]. This raises the urgency in expanding the role of universities and research organizations in trade associations and clusters. However, the current state of innovative development in many industrial areas has experienced significant complications under the pandemic and the resultant economic crisis. Intensification of international activity, creation and dissemination of knowledge and the synergistic effects of interaction between organizations may all contribute to a solution. Moreover, there is a growing general trend around the world in strengthening the role of economic cooperation. According to the World Bank's 2020 forecast, global gross domestic product (GDP) is expected to decline significantly in 2020 as a result of the COVID-19 pandemic [2,3]. World trade is 
also expected to decline by more than $13 \%$ in 2020 [3]. Experts are analyzing these changes, which are simultaneously affecting logistics processes in business and sparking certain trends to improve the situation. These include, for example, development of collaboration and pooling of services; implementation of the latest IT technologies; development of services and partnership agreements; and formulation of strategies and anticrisis plans within companies. These trends emphasize the need to analyze the advantages and disadvantages of existing systems of collaboration for the development of new and more efficient models of innovative clusters. Therefore, in the discussion of streamlining associated functioning and the proposal of new models of functioning and finding partners, we should observe numerous factors, perform thorough analyses and evaluations, create forecasts and assess risks.

Over the past fifty years, clustering, synergies and joint efforts in business have been a much-discussed topic in economic circles. From Porter to modern investigations, researchers have sought to demonstrate the efficiency and benefits of clusters, including improved access to suppliers and other limited resources, excellent knowledge and innovation, better opportunities, social networking capabilities, and competitiveness $[5,6]$. Recently, the role and position of universities in industrial clusters has received attention. Many authors $[5,7]$ believe that universities "open the door" to the world of international cooperation and partners and provides an irreplaceable research base. Also under discussion are the conditions for the creation of associations, such as first-rate, efficient organizational structures, coordination and information networks, stimulation of interaction, and issues of size and distribution of resources [7]. Some analyses of the conceptual gaps in cluster theory point to the inefficiency of large corporations' participation in clusters and argue that it is only beneficial to small businesses with the help of large partners [7].

Traditional methods of cluster model development include classic methods such as static analysis and structural design (SA/SD), IDEF methodology, and SADT methodology [9]. For greater effectiveness in the development of new architecture for innovative university-type cluster models, the tools of the IDEF0 methodology can be applied, allowing a more comprehensible and clear description of these architectural models. To solve problems in business process modelling, the Ramus Education software, which is a version of MS AllFusion, can be applied [10]. Ramus Education allows you to visually present any activity or structure in the form of a model which optimizes the work of an organization, designs the organizational structure, reduces costs, eliminates unnecessary operations and increases flexibility and efficiency. Ramus Education supports two methodologies: IDEF0 and DFD. It should be noted that any information system, regardless of the methodology in which it is modelled, cannot exist without computer support and a clear repository of information. Since the planned architecture is very complex, use of the most advanced data warehouse-the OLAP "cube" system-is proposed. This system can aid in the practical and technical application of a structural matrix system suitable for the creation of such networks and is described in more detail in [11]. The OLAP user obtains a natural, intuitive data model by arranging it in the form of multidimensional cubes. OLAP uses a multidimensional view of aggregated data for quick access and analysis of important information. OLAP systems provide analysts and managers with fast, consistent and interactive access to the internal data structure and the ability to transform source data to reflect the system's structure in the manner the user requires it. OLAP systems also allow viewing of data and the identification of patterns either visually or through simple methods (such as linear regression). The inclusion of neural network methods in its arsenal provides a significant extension of analytical capabilities [12].

The paper presents the results of a study aimed at analyzing the strengths and weaknesses of existing university-industry type clusters and developing its own model for improving cluster structures with the participation of universities and companies involved in the metallurgical industry. The study also proposes a new architectural model which contains elements of system analysis and logistic modelling for a universitytype cluster in the metallurgical industry. The effectiveness of this innovation was assessed on an association of universities and industry with the participation of Czech and Russian partners. The focus of research is the field of metallurgy and related industries. 


\section{EXPERIMENTAL PART}

The team of authors analyzed the information available regarding modern "university-industry-type" innovation clusters. Their analysis showed that the main weaknesses of existing modern innovation clusters of this type are mainly insufficient coordination structure and multilevel decision-making. This in turn raises other risks, such as the loss of meaning and interest for some partners in the cluster, which adversely affects the effectiveness of the entire cluster.

Building on the results of the analysis, the author team modelled an "industry-university-type" cluster (university cluster) which takes into account and attempts to eliminate the identified shortcomings. The links between Czech and Russian partners involved in the metallurgical industry were selected for analysis and are described in more detail in papers $[1,11]$. These papers present the outcomes of the planned project whose aim was the analysis of potential cooperation between the selected parties: Chotkovo enterprise which produces innovative paints and varnishes, the Dmitry Mendeleev University of Chemical Technology of Russia (MUCTR) and a RUSSIAN HELICOPTERS holding. The project also sought the reduction of costs in the development of innovative technology for the industrial electrolysis processes applied in the Russian Federation. To provide an international dimension in the newly designed cluster, VŠB-TUO was included.

To eliminate the identified shortcomings, a new coordination article in the form of a "coordination center" was introduced in the already existing cluster of the industry-university type. The list of key tasks which the coordination center and its basic architectural structure must fulfil is shown in Figure 1.

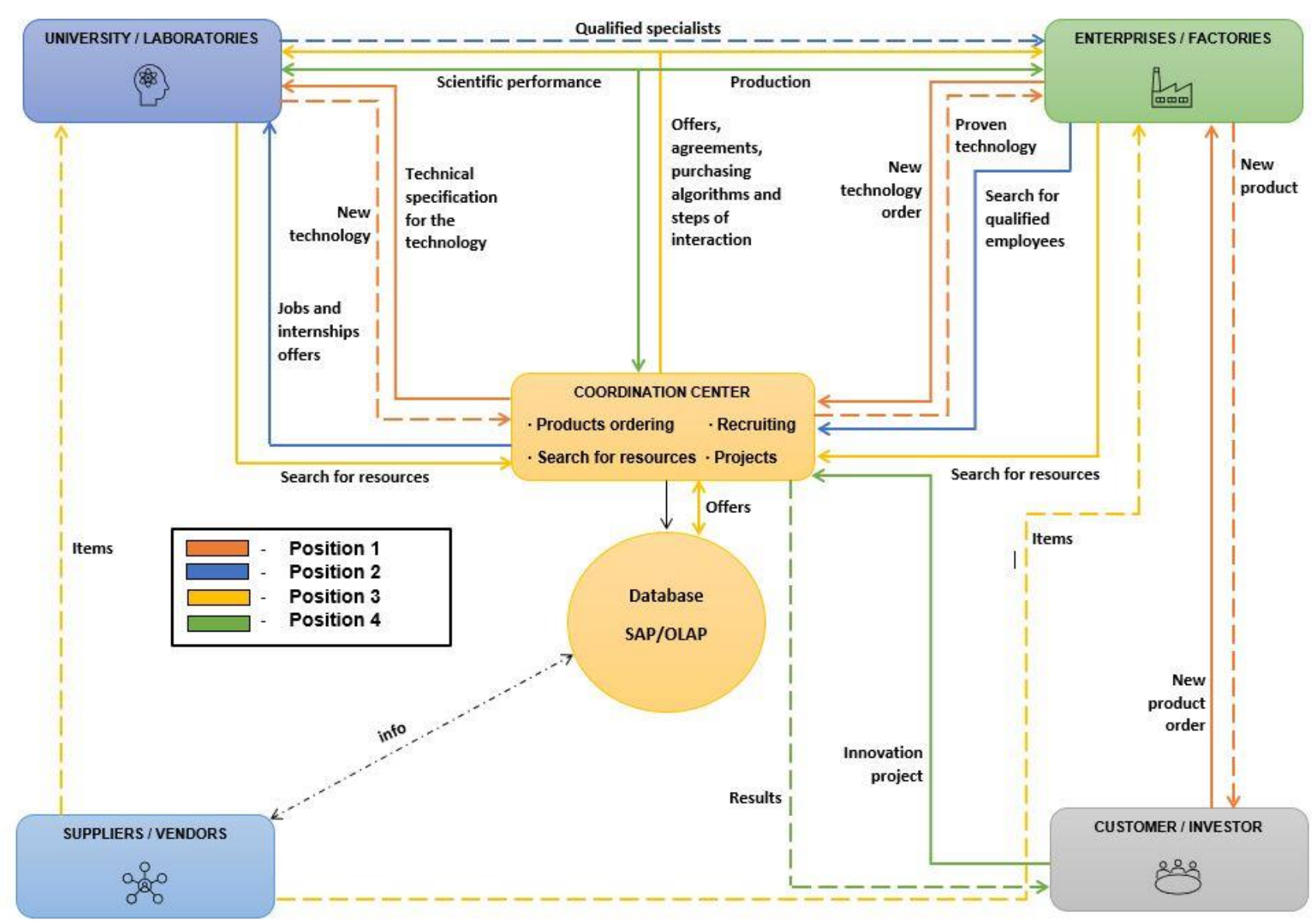

Figure 1 Architecture of the range of tasks of the coordination center [author's own elaboration] 
Where:

1 - actions for the coordination and selection of tasks related to the development or improvement of technologies;

2 - activities related to the recruitment and selection of qualified staff and professionals;

3 - actions related to fundraising and the simplification of purchasing procedures within the association;

4 - coordination of innovative projects.

To avoid errors during the management of such a complex multitasking system, its structural architecture must be crafted with care. This was done using simulation tools. The design of workflow modelling through Ramus computer software with the application on the IDEF0 methodology for a newly designed cluster is shown in Figure 2.

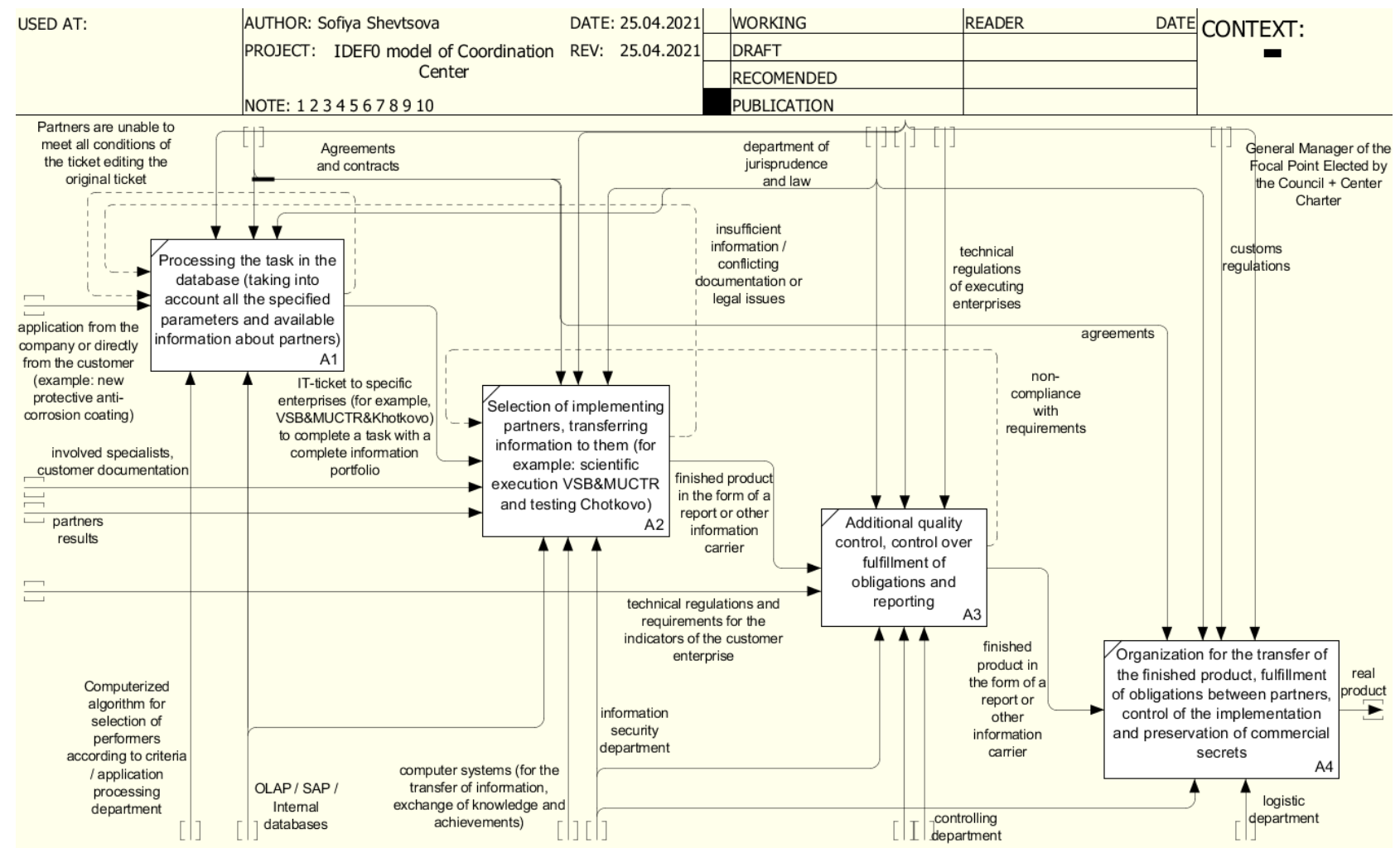

Figure 2 Design of the architecture for a new coordination center in an industry-university type cluster using the IDEF0 methodology [author's own elaboration]

An important component which allows the solution of key coordination problems and information gaps to be addressed is the design of the database. For a more efficient design of the "university-industry" cluster model, the SAP system for the management of logistics and business purchasing processes was used in combination with the OLAP system, which serves as a repository of information and allows the assignment of tasks between individual participants. As a result of layering the "cube" repository, information from structural matrices can be stored on the "face" area, and the remainder can be used for information related to activities, tasks and individual subjects (Figure 3). At the top edge of the cube, we observe the following parameters during the selection process: the participant's ability to complete the task (green - definitely yes, yellow - partially possible), innovative potential, and the number of people required. The necessary data can be added based on the available data from the individual participants in the cluster (the arrow indicates data is loading). The third area and the contents inside the cube contain additional data. As a result, in the first phase of decision- 
making for optimal task assignment, the most suitable individual participants for the task may be found quickly. The cube can be infinitely expanded, changed and given additions as internal and external factors change.

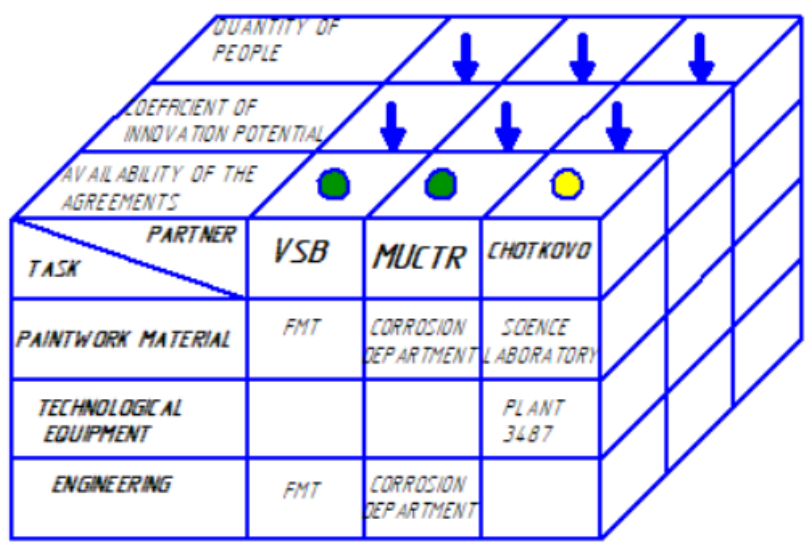

Figure 3 Example of an OLAP cube-type repository for solving tasks within the proposed cluster

\section{Results and discussion}

The newly designed cluster architecture - "Chotkovo Enterprise for the Production of Innovative Paints and Varnishes, VŠB-TUO, MUCTR and a RUSSIAN HELICOPTERS holding"-in combination with the introduction of a newly designed "coordination center" should lead to a reduction of information and logistics losses in production within the cluster. The amount of information and logistical losses of production can be determined according to the following relationships:

$I L L P=\left(C-C_{i i t}\right) * Q+\left(P_{i i t}-P\right) * Q+\left(P_{i i t}-C_{i i t}\right) *\left(Q_{i i t}-Q\right)$

or

$I L L P=\left(P_{i i t}-C_{i i t}\right) * Q_{i i t}-(P-C) * Q$

where:

ILLP - data and logical production losses

$C$ - actual production costs per unit

$C_{i i t}-$ actual production cost per unit which could be achieved with ideal information technologies

$Q$ - actual quantity of products produced

$Q_{i i t}-$ quantity of products which could be produced with ideal information technologies

$P$ - true unit price of the product

$P_{i i t}$ - product unit price which could be achieved with ideal information technologies

The amount of information and logical losses of production in the newly designed cluster was calculated according to relation 2, based on the available documents from the accounting and operational records of production at the Chotkovo company.

$I L P P=(7,17-4,62) * 464573,22-(7,17-5,43) * 464573,22=376304,3$

$3332070,59-100 \%$

$\frac{376304,3 * 100}{3332070,59}=11,26 \%$ 
Calculations show that information and logical production losses from inefficient information and logistics flows amounted to $11.2 \%$ of sales. The calculations compared the values of the original cluster and the newly designed cluster with the inclusion of a "coordination center" which coordinates all activities and optimizes all processes within the cluster.

\section{CONCLUSION}

Thus, the key to creating an improved, cluster-type unification model of the university and industrial sectors is to create a well-designed architecture which not only optimizes management processes, tunes algorithms and manages and coordinates information flows but also significantly reduces information loss in the enterprise. Because of its autonomy, this kind of structure does not raise any doubts regarding objectivity. The center, in turn, will be able to coordinate the tasks of different disciplines and directions.

This paper proposes a methodology which can be used to break down internal processes and automate them as much as possible through the use of algorithms. The information storage option proposed in the paper also optimizes the process and automatically processes huge amounts of data for quick retrieval by people performing tasks.

The new modelling will take clusters to a new level, make them more convenient, eliminate weaknesses and reinforce strengths. Given the current economic situation, this will then have a positive impact on the country's economy.

\section{ACKNOWLEDGEMENTS}

The work was supported by the specific university research of the Ministry of Education, Youth and Sports of the Czech Republic in VSB - Technical University of Ostrava No. SP2021/43 and SP2021/71.

\section{REFERENCES}

[1] SHEVTSOVA, S., ZUBAREV, A., MENSHIKOV, V. Approaches to the creation of innovative engineering center of chemical technology. Success in chemistry and chemical techology. 2017, vol. 21, no. 5 (186), pp. 105-107.

[2] VIDIA, C. T., PRABHEESH, K. P. Implications of COVID-19 pandemic on the global trade networks. Emerging Markets Finance and Trade. 2020, vol. 56, no. 10, pp. 2408-2421.

[3] World Bank. Global Economic Prospects Chapter 3. [online] 2020. [viewed: 2021-01-15]. Available from: https://pubdocs.worldbank.org/en/112641588788257004/Global-Economic-Prospects-June-2020-Topical-Issue-1

[4] BIALIC-DAVENDRA, M., KNAPKOVA, A., PAVELKOVA, D. Internationalization activities of the cluster organizations: factors which influence then. Transformations in Business \& Economics. 2015, vol. 14, no. 3C, p. 36.

[5] WOLFF, C. Management of an industry-university-cluster: ruhrvalley. In 6th Int. Scientific Conf. on Project Management in the Baltic Countries. 2017, pp. 370-380.

[6] CHEN, W., ZHANG, Y. C.,TIAN, S. H. Empirical research on innovation networks consisting of IndustryUniversity-Research institute in regional equipment manufacturing industry: a perspective of network structure and network cluster. China Soft Science. 2012, vol. 2, pp. 96-107.

[7] PAVELKOVA, D., ZIZKA, M., HOMOLKA, L., Do clustered firms outperform the non-clustered? Evidence of financial performance in traditional industries. Economic Research-Ekonomska Istraživanja. 2021, pp. 1-23.

[8] WOLFF, C., NUSEIBAH, A. A projectized path towards an effective industry-university-cluster: Ruhrvalley. In 2017 12th International Scientific and Technical Conference on Computer Sciences and Information Technologies (CSIT). 2017, vol. 2, pp. 123-131.

[9] WAISSI, G. R., DEMIR, M., HUMBLI, J. E., Automation of strategy using IDEF0-A proof of concept. Operations Research Perspectives. 2015, vol. 2, pp. 106-113. 
[10] Ramus Educational. Official Software information. [online] 2020. [viewed: 2021-03-09]. Available from: https://ramussoftware.com

[11] SHEVTSOVA, S., JANOVSKÁ, J., VILAMOVÁ, Š. Prospects of creating innovative business structures in the metallurgical industry. In METAL 2020: 29th International Conference on Metallurgy and Materials. Ostrava: TANGER, 2020.

[12] CECI, M., CUZZOCREA, A., MALEBRA, D. Effectively and efficiently supporting roll-up and drill-down OLAP operations over continuous dimensions via hierarchical clustering. Journal of Intelligent Information Systems. 2015, vol. 44, no. 3, pp. 309-333. 